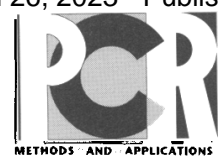

\title{
An Infrared Fluorescent dATP for Labeling DNA
}

\author{
David L. Steffens, ${ }^{1,4} \mathrm{Gi}$ Y. Jang, ${ }^{1}$ Scott L. Sutter, ${ }^{1}$ John A. Brumbaugh, ${ }^{1}$ Lyle R. Middendorf, ${ }^{1}$ \\ Klaus Mühlegger, ${ }^{2}$ Elaine R. Mardis, ${ }^{3}$ Lori A. Weinstock, ${ }^{3}$ and Richard K. Wilson ${ }^{3}$
}

\author{
${ }^{1}$ Research \& Development Department, Biotechnology Division, LI-COR, Inc., Lincoln, Nebraska 68504; ${ }^{2}$ Boehringer \\ Mannheim GmbH, R\&D Biochemicals, D-82377 Penzberg, Germany; ${ }^{3}$ Washington University School of Medicine, Genome \\ Sequencing Center, St. Louis, Missouri 63108
}

\begin{abstract}
Near-infrared fluorescence provides a nonradioactive method of detection with high sensitivity and low background. An infrared fluorophore has been attached covalently to the nucleotide deoxyadenosine triphosphate (dATP) to provide a reagent for enzymatic labeling of various types of DNA molecules and for facilitating their detection with an automated DNA sequencing and analysis system. DNA sequencing reaction products can be labeled internally by performing limited polymerization utilizing infrared-labeled dATP (IR-dATP) as the sole source of adenine deoxynucleotide prior to a dideoxy-specific termination reaction. PCR products can be labeled fluorescently by the addition of limited quantities of IR-dATP to the amplification reaction. This latter strategy has been utilized for detection of short tandem repeat polymorphisms (STRPs) which are useful for gene mapping, genetic diagnostics, forensic analysis, and paternity testing. Restriction fragments can be labeled also by fill-in reactions of appropriate $5^{\prime}$ overhangs. Diminutive amounts of such fluorescently labeled DNA molecules can be visualized rapidly and conveniently using infrared detection technology.
\end{abstract}

resent-day molecular biology detection systems strive to achieve high sen- sitivity while avoiding the troublesome use of radioactivity. Fluorescent reporter groups are one approach to attaining these goals. A fluorophore can absorb and radiate electromagnetic radiation at extremely fast rates $\left(10^{-15}\right.$ and $10^{-8} \mathrm{sec}$, respectively), thus producing a large signal from a limited number of molecules. ${ }^{(1)}$ Sensitivity is enhanced also by measuring the emitted fluorescence against a background of virtually zero. The molecule of interest can be labeled fluorescently by direct covalent attachment to the fluorophore or through indirect means by use of avidin-biotin or antigen-antibody binding.

Automated DNA sequencers utilize fluorescence detection of gel-separated, dye-labeled fragments. Labeled species incorporated into sequencing fragments include oligonucleotide primers, ${ }^{(2,3)}$ dideoxynucleotide triphosphate terminators, ${ }^{(4,5)}$ and deoxynucleotides. ${ }^{(6-8)}$ Subsequent detection of the fluorescent sequencing bands facilitates determination of the DNA sequence. These methods have utilized predominantly the visible portion of the spectrum. The nearinfrared (NIR) region of the spectrum (700-3000 nm) offers advantages over visible wavelengths, because absorbance and fluorescence emission in the NIR from biomolecules and solvents is negligible. ${ }^{(9,10)}$ As a result, background is extremely low and high sensitivity can be achieved. Several polymethine cyanine dyes have been developed that have good fluorescent properties-high molar absorptivities and fluorescence quantum yields. ${ }^{(1-13)}$ One of these, a symmetric heptamethine cyanine dye (IRD40; Fig. 1A), contains sulfobutyl groups for enhanced water solubility and an isothiocyanate group to enable covalent attachment to primary amine functional groups. Although NIR dyes were originally developed as labeling reagents for analytical determination of proteins, we demonstrate that additional types of biomolecules can be labeled with NIR fluorescence also. ${ }^{(12,14)}$

Previously, we have developed technology utilizing NIR fluorescence for automated sequencing of DNA. ${ }^{(15)}$ Initial sequencing experiments utilized oligonucleotides containing a $5^{\prime}$ primary amine attached covalently to the IRD40 fluorophore to assess the utility of this dye for automated DNA sequencing. ${ }^{(16)}$ Standard sequencing methodologies performed with these labeled primers produced high-quality sequencing ladders and accurate DNA sequence data. In this report we describe an infrared fluorescently labeled deoxyadenosine triphosphate (Fig. 1B), which can be utilized as a versatile mechanism for enzymatically labeling various types of DNA molecules. Sequencing fragments can be labeled internally, thus obviating the need for fluorescent primers. PCR products, such as short tandem repeat polymorphisms (STRPs), and restriction fragments can be labeled also utilizing this molecule. These various types of DNA molecules can be visualized and analyzed rapidly and conveniently using high-sensitivity infrared detection technology.

${ }^{4}$ Corresponding author. 


\section{STEFFENS ET AL.}
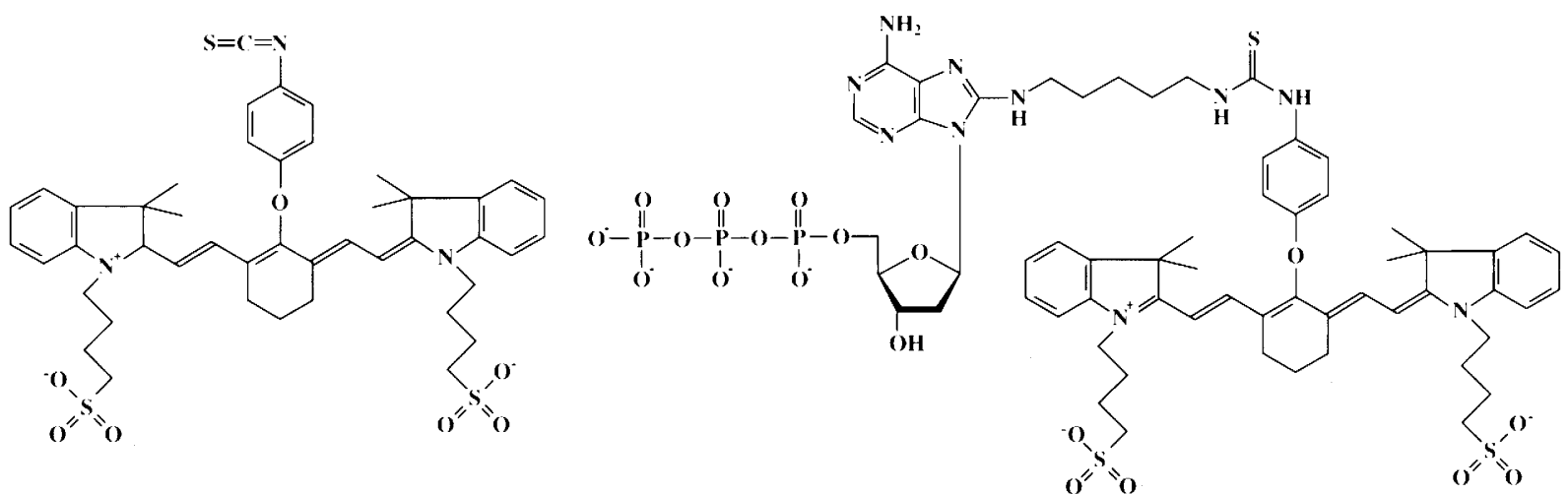

FIGURE $1(A)$ Structure of NIR fluorescent dye IRD40 (4-[2-[4-[(4-isothiocyanatophenyl)oxy]-7-[3,3-dimethyl-1-(4-sulfonatobutyl)indolin-2-ylidenel-3,5-(propane-1,3-diyl)-1,3,5-heptatrien-1-yl]-3,3-dimethyl-3H-indoliolbutanesulfonate). (B) Structure of IRD40 covalently attached to deoxyadenosine triphosphate (IR-dATP).

Experiments aimed at determining the limit of detection of fluorescently labeled primers using NIR detection technology indicate that $\sim 15$ attomoles (amoles) can be detected. ${ }^{(17)}$ In our experience with visible fluorescence instrumentation, we have detected as little as $\sim 54$ amoles of a difluoresceinated primer. (18) Extrapolation of this data suggests that $\sim 108$ amoles of a monofluoresceinated primer would be its limit of detection. Hence, NIR technology is approximately seven times more sensitive than visible fluorescence methodology. Another advantage of NIR technology is that the instrumentation involved is more reliable (longer component lifetimes), smaller, and less costly than visible fluorescence systems. ${ }^{(15)}$ Excitation is accomplished using a low-power $(<0.5$ $W$ ) infrared emitting laser diode. A lownoise silicon avalanche photodiode is utilized for detection of the emitted fluorescence. The small size and weight of these components facilitate direct mounting on the scanning platform, thus allowing precise focusing upon the gel. Accurate focusing across the width of the gel is also enhanced by use of extremely flat, inexpensive soda lime glass plates (resulting in extremely flat gels), which can be used in NIR systems because of the minimal background fluorescence. These characteristics provide the motivation for NIR utilization and our efforts involving labeling of diverse types of nucleic acid molecules.

\section{MATERIALS AND METHODS}

\section{Infrared-labeled dATP}

NIR fluorescent dye IRD40 was covalently attached to dATP at the C-8 position of the heterocyclic ring via a 6-atom spacer arm that terminated with a reactive primary amine (Boehringer Mannheim; Penzberg, Germany). Approximately 50 nmoles of amino-terminated linker arm dATP was reacted with 500 nmoles of IRD40 dye (initially dissolved in dimethylformamide) in a 200 $\mu \mathrm{l}$ reaction volume containing $67 \%$ (vol/ vol) dimethylformamide and $67 \mathrm{~mm}$ sodium carbonate buffer ( $\mathrm{pH} 9.5$ ). The reaction was incubated at room temperature for 4-16 hr in the dark, with occasional mixing. Coupling the isothiocyanate group of the dye to an amino group yields a stable thiourea attachment to the nucleotide (Fig. 1B). Excess unreacted dye was removed from the labeled dATP by reverse-phase highperformance liquid chromatography (HPLC). The spacer arm and its position of attachment reduce steric hindrance of the dye with base-pairing regions of adenine and the $5^{\prime} \alpha$-phosphate of the nucleotide, both of which are necessary for exploitable incorporation of the labeled nucleotide into a growing DNA chain.

\section{Sequencing Reactions}

Single-stranded M13mp18 or M13 subclones containing fragments of the Caenorhabditis elegans genome were se- quenced with a universal M13 Forward (-29) primer using a Sequenase 7-deazadGTP Sequencing Kit from United States Biochemical Corp. (USBC; Cleveland, $\mathrm{OH}) .{ }^{(19)}$ All reagents and enzymes are from USBC unless designated otherwise. Template DNA $(1.0 \mu \mathrm{g})$ in a $10-\mu \mathrm{l}$ volume of $1 \times$ Sequenase buffer was annealed to either unlabeled primer (2 pmoles) or IRD40 $5^{\prime}$ end-labeled primer ( 3 pmoles) by incubation at $95^{\circ} \mathrm{C}$ for 5 min, followed by a $50^{\circ} \mathrm{C}$ incubation for 10-20 min, and final placement on ice. Extension of the primer and IR-dATP incorporation were achieved by adding $1.3 \mu \mathrm{l}$ of $\mathrm{H}_{2} \mathrm{O}, 1.2 \mu \mathrm{l}$ of $20 \mu \mathrm{M}$ IR-dATP, $0.5 \mu \mathrm{l}$ of $\alpha$-thio-dNTP labeling mix (200 $\mu \mathrm{M}$ each of $\alpha$-thio-dCTP, $\alpha$-thio-dGTP, $\alpha$-thio-dTTP), and $2.0 \mu$ l of diluted enzyme mix [6.5 $\mu$ l of $50 \%$ glycerol; $20 \mathrm{~mm}$ Tris- $\mathrm{HCl}$ at $\mathrm{pH} 7.5$ (both Molecular Biology Grade, Sigma Chemical; St. Louis, $\mathrm{MO}), 1.0 \mu \mathrm{l}$ of Sequenase DNA polymerase $(13 \mathrm{U} / \mu \mathrm{l})$, and $0.5 \mu \mathrm{l}$ of pyrophosphatase $(5 \mathrm{U} / \mathrm{ml})]$ to the annealed primer-template. This mixture was incubated at $37^{\circ} \mathrm{C}$ for $10 \mathrm{~min}$. After incubation, an additional $0.3 \mu$ l of undiluted Sequenase enzyme was added to each labeling reaction; also at this time, $3.0 \mu \mathrm{l}$ of $\mathrm{H}_{2} \mathrm{O}$ and $2.0 \mu$ l of diluted enzyme mix were added to the annealed labeled primer reaction. The reaction mixtures were divided by placing 3.5- $\mu$ l aliquots into four termination tubes containing Sequenase $4 \times$ relative extension/termination mixes [1.0 $\mu \mathrm{l}$ of standard termination mix plus $1.5 \mu \mathrm{l}$ of $180 \mu \mathrm{M}$ all four 
dNTPs (Boehringer Mannheim; Indianapolis, IN) in $50 \mathrm{~mm} \mathrm{NaCl}$. Dideoxy termination reactions were incubated at $37^{\circ} \mathrm{C}$ for $10 \mathrm{~min}$ prior to addition of $4 \mu \mathrm{l}$ of Stop solution. Unincorporated IRdATP can be removed by ethanol precipitation, gel filtration chromatography, or ultrafiltration prior to addition of Stop solution, if desired.

Double-stranded plasmid pBluescript II SK + (Stratagene; La Jolla, CA) was denatured using an alkali denaturationethanol precipitation procedure. ${ }^{(20)}$ The DNA pellet was redissolved in $10 \mu \mathrm{l}$ of $1 \times$ Sequenase buffer containing 5 pmoles of unlabeled primer and incubated at $37^{\circ} \mathrm{C}$ for $15-30 \mathrm{~min}$ to anneal primer to template. This annealing step was followed by the remainder of the internal label protocol described above for single-stranded templates. Sequencing reactions comparing unmodified dNTPs to $\alpha$-thio-dNTPs in the labeling reaction were performed as above, where the unmodified dNTP labeling mix contained $200 \mu \mathrm{M}$ each of dCTP, dGTP, and dTTP. Sequencing reactions were denatured for $3 \mathrm{~min}$ at $95^{\circ} \mathrm{C}$ and loaded onto a $41-\mathrm{cm}$ denaturing $6 \%$ Long-Ranger gel (AT Biochem; Malvern, PA), and electrophoresed on a LI-COR model 4000 automated DNA sequencer.

\section{STRP Reactions}

PCR amplification was performed in a $10-\mu l$ volume containing $50 \mathrm{mM} \mathrm{KCl} ; 1.5$ $\mathrm{mM} \mathrm{MgCl}_{2} ; 10 \mathrm{~mm}$ Tris- $\mathrm{HCl}(\mathrm{pH} 8.3$ at $20^{\circ} \mathrm{C}$ ); 7 pmoles of each primer; $50 \mathrm{ng}$ of human genomic DNA; $200 \mu \mathrm{M}$ each of dATP, dCTP, 7-deaza-dGTP, dTTP; $1 \mu \mathrm{M}$ IR-dATP; and 1 unit of Taq polymerase from Boehringer Mannheim (Indianapolis, IN). Primer sequences were $5^{\prime}$ TGCATACCTGTACTACTTCAG-3' for the forward primer and 5'-TCCTTTGTTGCAGATTTCTTC-3' for the reverse primer. Thermal cycling conditions were $95^{\circ} \mathrm{C}$ for $20 \mathrm{sec}, 55^{\circ} \mathrm{C}$ for $20 \mathrm{sec}$, and $72^{\circ} \mathrm{C}$ for $30 \mathrm{sec}$ for 35 cycles using a Perkin-Elmer GeneAmp PCR System 9600. Unincorporated IR-dATP was removed using Microcon-100 concentrators from Amicon (Beverly, MA), according to the manufacturer's instructions. The final volume was $-5 \mu \mathrm{l}$, to which 2.5 $\mu \mathrm{l}$ of Sequenase Stop solution was added. A $1.5-\mu \mathrm{l}$ aliquot was loaded onto a $25-\mathrm{cm}$ denaturing $7 \%$ Long-Ranger gel and electrophoresed on a LI-COR model $4000 S$ automated DNA sequencer.

\section{Restriction Fragment Labeling}

pBluescript II SK + plasmid (7 $\mu$ g) (Stratagene; La Jolla, CA) was digested with either HinfI or Sau3AI restriction endonucleases (New England Biolabs; Beverly, MA). The digests were extracted sequentially with neutralized aqueous phenol, 50:50 phenol + chloroform, and chloroform. One-tenth volume of $3 \mathrm{M}$ sodium acetate was added and DNA fragments precipitated with 3 volumes of $100 \%$ ethanol. DNA was pelleted in a refrigerated microcentrifuge, washed with $70 \%$ ethanol, and air-dried briefly. The pellet was dissolved in $10-\mu$ l of 10 $\mathrm{mm}$ Tris- $\mathrm{HCl}\left(\mathrm{pH} 7.5\right.$ at $\left.20^{\circ} \mathrm{C}\right)$ and $1 \mathrm{mM}$ EDTA. Complete digestion was confirmed by agarose gel electrophoresis, which produced the expected banding pattern for both digests. Digested DNA $(0.5 \mu \mathrm{l})$ was placed in a $10-\mu \mathrm{l}$ reaction tube containing $24 \mathrm{~mm}$ Tris- $\mathrm{HCl}(\mathrm{pH}$ 7.5), $12 \mathrm{mM} \mathrm{MgCl}_{2}, 30 \mathrm{mM} \mathrm{NaCl}$, and 1 $\mu \mathrm{M}$ IR-dATP. In addition, $1 \mu \mathrm{M}$ dGTP was included with Sau3AI-digested DNA because it must be incorporated into the overhang prior to dATP. Labeling was initiated by addition of $1.2 \mu \mathrm{l}$ of a diluted enzyme mixture (Sequenase plus pyrophosphatase) as utilized for sequencing reactions described above. Reactions were incubated at $37^{\circ} \mathrm{C}$ for 30 min followed by the addition of $6 \mu 1$ Sequenase Stop solution. Samples were diluted 1:30 with $\mathrm{H}_{2} \mathrm{O}+$ Stop solution (60: 40 ), denatured at $95^{\circ} \mathrm{C}$ for $1-2 \mathrm{~min}$, and loaded and electrophoresed in the same manner as STRP reactions above.

\section{RESULTS AND DISCUSSION}

\section{Spectroscopy}

The absorption and fluorescence emission spectra of IR-dATP are shown in Figure 2. The strong NIR absorbance of the fluorophore $\left(\epsilon=140,000 \mathrm{M}^{-1} \mathrm{~cm}^{-1}\right.$ for IRD $40^{(12)}$ relative to the ultraviolet (UV) absorbance of the nucleotide $\left(\epsilon=15,400 \mathrm{M}^{-1} \mathrm{~cm}^{-1}\right.$ for dATP) ${ }^{(21)}$ can be observed clearly. The high NIR molar absorptivity enhances the overall sensitivity. IR-dATP has a NIR absorption maximum of $770 \mathrm{~nm}$ and fluorescence emission maximum of $790 \mathrm{~nm}$ allowing detection with previously described infrared imaging systems. ${ }^{(15)}$ The UV absorption maximum of the adenine deoxynucleotide is shifted from $259 \mathrm{~nm}$ (for $\mathrm{dATP}^{(21)}$ to $278 \mathrm{~nm}$ by attachment of the linker arm plus fluorophore to the heterocyclic purine ring.

\section{DNA Sequencing}

The large quantity of DNA sequencing being performed currently probably presents the greatest requirement for labeling of DNA molecules. Figure 3 demonstrates the use of IR-dATP for labeling DNA sequencing fragments utilizing a modified bacteriophage T7 DNA polymerase (Sequenase). ${ }^{(2)}$ This enzyme displays high processivity and an ability to incorporate a number of nucleotide analogs, including infrared fluorescently labeled dATP, into the growing DNA chain. A labeling step with IR-dATP as the sole source of adenine nucleotide incorporates fluorescent label into sequencing fragments prior to a dideoxynucleotide-specific chain termination reaction. This is analogous to the protocol performed with radiolabeled deoxynucleotides in the original modified T7 polymerase methodology. An IRD40 5'end-labeled primer sequencing reaction (lanes 1-4) is directly compared with an IR-dATP internal label reaction (lanes 5-8) in Figure 3A. Both reactions utilized identical single-stranded M13mp18 template and universal M13 Forward primer (unlabeled in the latter case) and produced quite similar results indicating that both labeling strategies are capable of generating high-quality DNA sequence data. The labeled primer sequencing bands migrate somewhat slower because of increased electrophoretic drag by the fluorophore located at the terminus of the DNA fragments. Figure 3B shows similar high-quality sequencing results obtained with a double-stranded plasmid. This IR-dATP labeling protocol eliminates the need for labeled sequencing primers, thus making NIR primer walking strategies feasible.

The results shown in Table 1 summarize our success rate with the incorporated labeling protocol for single-stranded DNA sequencing in the context of the $C$. elegans genome sequencing project. It should be noted that the majority of the templates used in incorporated labeling reactions described here had given poor results by standard cycle sequencing procedures, because of the presence of either homopolymeric runs of C's or G's or of dinucleotide repeat regions ( $\mathrm{CA}^{\prime} \mathrm{s}$ or $\mathrm{GA}^{\prime} \mathrm{s}$ ). 


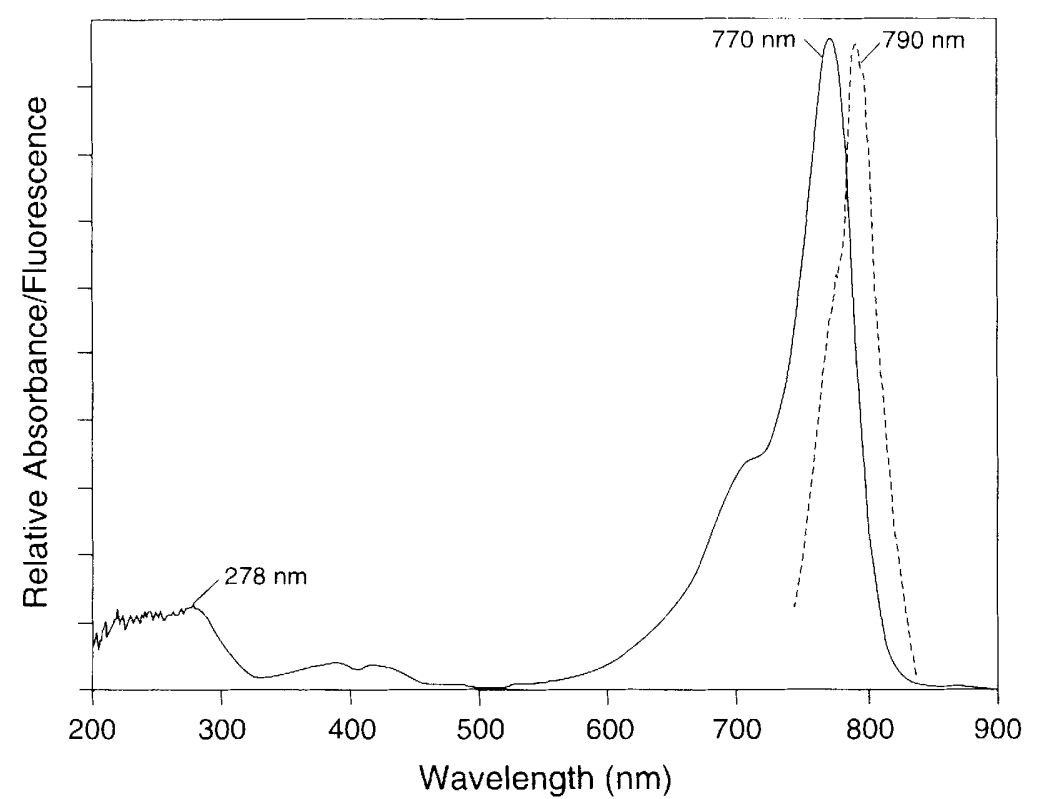

FIGURE 2 Absorption (solid curve) and fluorescence emission (dashed curve) spectra of IR-dATP dissolved in $100 \mathrm{~mm}$ phosphate buffer ( $\mathrm{pH} \mathrm{7.0)}$. The absorbance maximum at $770 \mathrm{~nm}$ is caused by the NIR fluorophore; the 278-nm maximum corresponds to the adenine base.
A

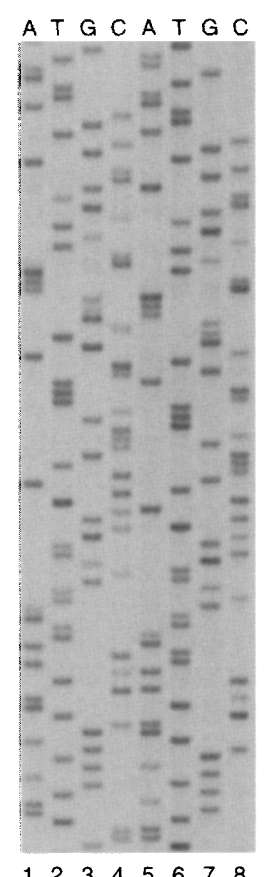

B

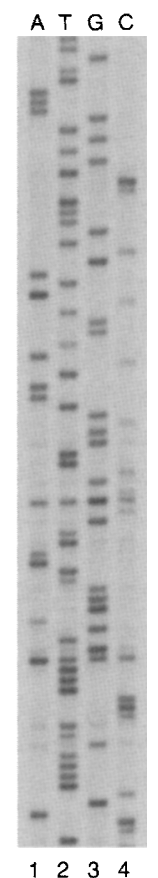

FIGURE 3 Sequencing of DNA using IR-dATP. (A) Single-stranded M13mp18 sequenced with a universal M13 Forward primer $5^{\prime}$ end-labeled with IRD40 (lanes 1-4) or with unlabeled primer using IR-dATP (lanes 5-8). (B) Double-stranded pBluescript II $\mathrm{SK}+$ sequenced with a universal M13 Forward primer using IR-dATP.
We define success as the acquisition of usable sequence data through the problem region. The use of a strategy combining the processivity of Sequenase with the flexibility afforded by the incorporated labeling and custom oligomers allows us to solve $-70 \%$ of these difficult repeat regions. In general, successful sequencing reactions through these regions yield -200 - to 500-base read lengths, depending on the severity of the problem region. Failures here typically are caused by the inability of the polymerase to maintain high fidelity through the region. Enhanced performance of the universal M13 Forward (-29) primer may be the result of optimization for this binding site, combined with extensive experience in its use. ${ }^{(19)}$ Currently, we are experimenting with reaction modifications aimed at increasing the percentage readthrough achieved by the polymerase in these difficult regions. Our overall success in sequencing reactions using the incorporated labeling strategy indicates that it is a reliable, robust procedure for a variety of sequencing templates and primers.

Multiple incorporation of IR-dATP into sequencing fragments would produce multiple bands for each dideoxy termination position because of the differences in electrophoretic mobility of identical DNA molecules with different numbers of infrared fluorophores attached. In our experience with a number of different templates and primers, we have not observed multiple banding even when sequencing fragments are separated on high-resolution $66-\mathrm{cm}$ sequencing gels, indicating that all detectable fragments contain an identical number of fluorophores. Identical experimental observations have been obtained with fluorescein-15-dATP using visible wavelength instruments. ${ }^{(23)}$ In addition, Figure $3 \mathrm{~A}$ depicts a direct comparison of a sequencing reaction using labeled primer (synthesized containing only one fluorophore; lanes 1-4) to an internal label reaction (lanes 5-8). Because the NIR fluorophore is so large ( $\sim 1000$ daltons) it is expected that multiply labeled strands would migrate more slowly than singly labeled strands regardless of label placement. Because the internally labeled fragments migrate faster than the labeled primer fragments, it is reasonable to conclude that they contain only one fluorophore.

We hypothesize that incorporating IR-dATP into the growing DNA chain is difficult for the polymerase because of the bulk ( -1000 daltons) and hydrophobic character of the fluorophore. When one IR-dATP molecule is incorporated, further polymerization may be hindered severely by the low dNTP concentration within the labeling reaction and by the absence of unmodified dATP. When higher concentrations of dNTPs (including unmodified dATP) are added during the dideoxy termination reaction, polymerization continues until dideoxy-specific termination occurs, resulting in sequencing fragments singly labeled with the fluorophore. A similar scenario is postulated for incorporation of fluores cein-15-dATP, which contains a visible wavelength fluorophore that is only $\sim 50 \%$ of the molecular mass of the NIR fluorophore. ${ }^{(23)}$ Further experimentation is required to clarify the molecular mechanisms of the labeled nucleotide incorporation.

Incorporation of IR-dATP into DNA is not accomplished as readily as unmodified dATP because of the presence of the fluorophore. We have found that replacing unmodified dNTPs (dCTP, dGTP, and dTTP) in the labeling reaction with $\alpha$-thio-dNTPs, enhances the incorporation of IR-dATP into the resulting sequencing fragments. $\alpha$-ThiodNTPs have been utilized previously 
TABLE 1 Success Rate of Labeling Protocol for C. elegans Genome Sequencing Project

\begin{tabular}{lcc}
\hline Template type & $\begin{array}{l}\text { Oligonucleotide type (universal } \\
\text { or custom) }\end{array}$ & $\begin{array}{l}\text { Successful reactions/total } \\
(\%)\end{array}$ \\
\hline ssM13 subclones & universal (-29) primer \\
ssM13 subclones & custom & $34 / 36(94.4)$ \\
\end{tabular}

to improve banding patterns in automated DNA sequencing. ${ }^{(5)}$ In NIR internal label automated sequencing $\alpha$ thio-nucleotides increase signal intensity approximately two- to fourfold, as shown in Figure 4, for both single- and double-stranded templates. The exact mechanism of this enhancement currently is not known, although the decreased affinity of the $\mathrm{T} 7$ polymerase for $\alpha$-thio-dNTPs relative to deoxynucleotides may enhance the probability of incorporating the labeled dATP into the synthesized strand.
A

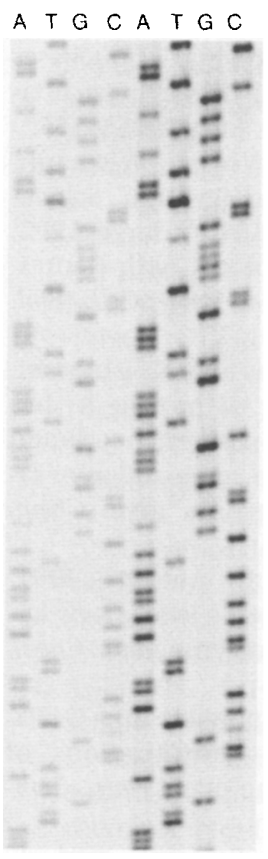

$\begin{array}{llllllll}1 & 2 & 3 & 4 & 5 & 6 & 7 & 8\end{array}$

\section{B}

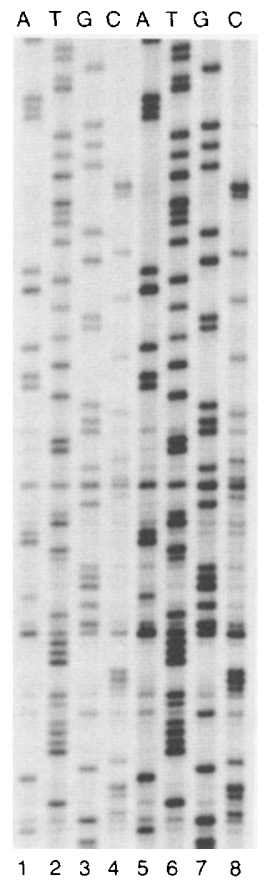

FIGURE 4 Effect of $\alpha$-thio-dNTPs on IR-dATP incorporation. (A) Single-stranded M13mp18 sequenced using a universal M13 Forward primer with unmodified dNTPs (dCTP, dGTP, and dTTP) (lanes 1-4) or $\alpha$-thio-dNTPs (lanes $5-8$ ) in the labeling reaction. (B) Doublestranded pBluescript II SK + sequenced using a universal M13 Forward primer with unmodified dNTPs (lanes 1-4) or $\alpha$-thio-dNTPs (lanes 5-8) in the labeling reaction.

\section{PCR}

The development of PCR methodology for amplification of low-copy-number DNA targets has greatly enhanced molecular analysis of the genome. ${ }^{(24,25)}$ STRPs (repeats of di-, tri-, or tetranucleotide sequences varying in number of repeat units among individuals) have proven to be of great use in gene mapping, genetic diagnostics, paternity testing, and forensic analysis. ${ }^{(26)}$ Conventionally, STRPs are detected by performing PCR amplification of genomic DNA with two defined primers flanking the polymorphic repeat site with radiolabeled deoxynucleotide present in the reaction. More recently, however, automated detection systems using fluorescently labeled PCR primers and laser irradiation have yielded rapid and consistent results with higher throughput. $^{(27,28)}$

A fluorescently labeled nucleotide, such as IR-dATP, can also be utilized for labeling PCR products by including a limited quantity (200:1 ratio of unlabeled to labeled dATP) in the amplification reaction. Figure 5 shows the STRP patterns of three nuclear families utilizing IR-dATP labeling with primers that amplify the $B R C A 1$ region on chromosome $17 \mathrm{q} 12-\mathrm{q} 21 .{ }^{(29)}$ This locus cause of its influence on susceptibility to breast and ovarian cancer. ${ }^{(30)}$ The fragments range from 235 to 259 bases and show inheritance of one maternal and one paternal allele in each child clearly. The two bands present for each allele are caused by the incorporation of NIR label into both strands of the PCR product, which possess different electrophoretic mobilities because of differences in base composition. Multiple banding caused by multiple incorporation of IR-dATP has not been observed. The 200:1 ratio of dATP to IR-dATP was empirically determined to be optimal for maximum incorporation of NIR label into PCR products without affecting the PCR. has drawn intense interest recently be-
Higher ratios of IR-dATP do not yield a greater signal but increase the possibility of multiple labeling or inhibiting fulllength product formation.

\section{Restriction Fragment Labeling}

The presence of $5^{\prime}$ overhangs containing deoxythymidine on certain restriction fragments provides a suitable structure for labeling such forms of DNA. A 5' overhang can be filled in by a polymerase if appropriate nucleotides are available. We have used this strategy to label fluorescently HinfI and Sau3AI digests of pBluescript II SK + utilizing IRdATP (Fig. 6). HinfI overhangs require only IR-dATP, whereas Sau3AI overhangs require $\mathrm{dGTP}$ prior to incorporation of adenine deoxynucleotide. Sequenase DNA polymerase, which is able to incorporate IR-dATP into sequencing fragments, also can utilize this labeled nucleotide for $5^{\prime}$ overhang fill-in reactions. Restriction fragment sizes were confirmed by comparison with a standard sequencing ladder and match predicted sizes and agarose gel band pat-

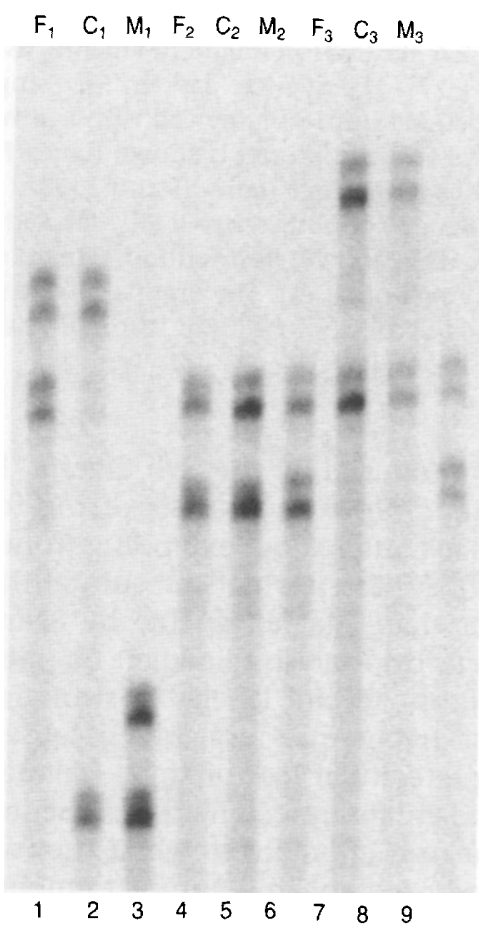

FIGURE 5 Allelic profiles of three nuclear families (family 1, lanes $1-3$; family 2 , lanes 4-6; and family 3, lanes 7-9) for locus BRCA1. PCR products were labeled using IR-dATP. (F) father; (C) child; $(\mathrm{M})$ mother. 


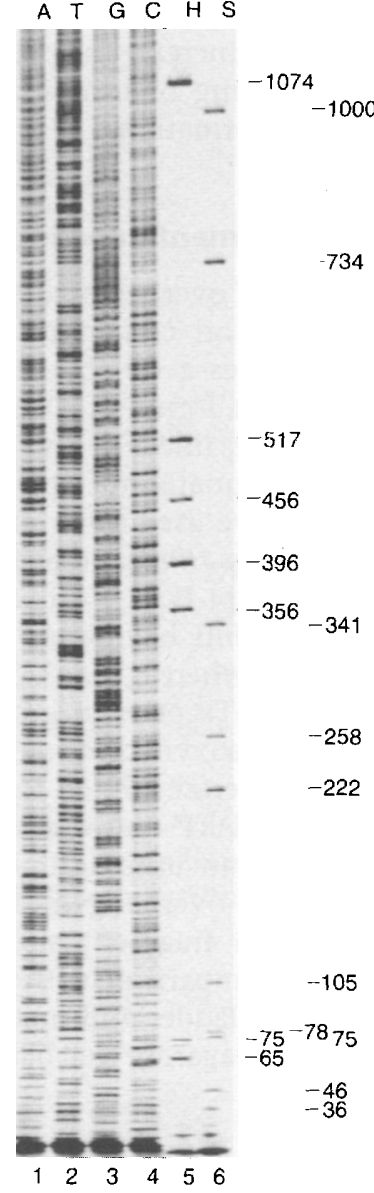

FIGURE 6 Restriction fragment labeling using IR-dATP. A sequence ladder of singlestranded M13mp18 sequenced with a universal M13 Forward primer is shown (lanes 1-4) together with Hinfl (lane 5) and Sau3AI digests (lane 6) of pBluescript II SK + labeled using IR-dATP. (Right) Restriction fragment size (in number of bases). The original image was reduced vertically to $15 \%$ of its original size.

terns produced by the two digests. The dynamic range of analysis of the fragments is quite good, extending from 36 to 1074 bases, which is substantially better than that attainable by agarose gel electrophoresis. Smaller fragments $(<100 \mathrm{bp})$ are not labeled as strongly as larger fragments, probably because of the preferential loss of small fragments in the ethanol precipitation subsequent to the restriction digest, where they were initially present in equimolar amounts. High-resolution electrophoresis of labeled restriction fragments on a 41- or $66-\mathrm{cm}$ denaturing gel reveals two bands for each fragment (not shown) because of differences in base composition between the two denatured complemen- tary strands. Other types of restriction fragment termini ( $3^{\prime}$ overhangs, blunt ends, 5' overhangs lacking a deoxythymidine) can be rendered suitable for fillin labeling by ligation of an appropriate oligonucleotide adaptor to produce an appropriate $5^{\prime}$ overhang.

\section{CONCLUSIONS}

Certain DNA polymerases such as modified $T 7$ polymerase (Sequenase) and Taq polymerase have the ability to incorporate modified nucleotides during the synthesis of a DNA polymer. In the case of IR-dATP, the modification consists of a fluorophore which is approximately twice the molecular mass of the unmodified nucleotide. Nonetheless, this molecule facilitates a novel NIR labeling strategy that permits high-sensitivity infrared analysis of a wide variety of DNA structures.

Additional applications of this reagent can be envisioned. Alteration of reaction conditions or alternate polymerases may allow multiple incorporation of IR-dATP in random priming and/or nick translation protocols to produce NIR-labeled hybridization probes. Such probes would allow NIR technology to be applied to analysis of Southern, Northern, and dot blots, as well as use in fluorescence in situ hybridization (FISH). Another possibility might be to include this reagent in in situ PCR reactions to facilitate NIR analysis of certain cytologic and histologic features, thus eliminating the need for postamplification hybridization detection.

\section{ACKNOWLEDGMENTS}

We thank Narasimhachari Narayanan for critical reading of this manuscript.

The publication costs of this article were defrayed in part by payment of page charges. This article must therefore be hereby marked "advertisement" in accordance with 18 USC section 1734 solely to indicate this fact.

\section{REFERENCES}

1. Willard, H.H., L.L. Merritt, Jr., and J.A. Dean. 1974. Instrumental methods of analysis, 5th ed., pp. 133-134. D.Van Nostrand Co., New York.

2. Smith, L.M., J.Z. Sanders, R.J. Kaiser, P. Hughes, C. Dodd, C.R. Connell, C. Heiner, S.B.H. Kent, and L.M. Hood. 1986. Fluorescence detection in automated DNA sequence analysis. Nature 321: 674-679.
3. Ansorge, W., B.S. Sproat, J. Stegemann, and C. Schwager. 1986. A nonradioactive automated method for DNA sequence determination. J. Biochem. Biophys. Methods 13: 315-323.

4. Prober, J.M., G.L. Trainor, R.J. Dam, F.W. Hobbs, C.W. Robertson, R.J. Zagursky, A.J. Cocuzza, M.A. Jensen, and K.R. Bauermeister. 1987. A system for rapid DNA sequencing with fluorescent chainterminating inhibitors. Science 238: 336341.

5. Lee, L.G., C.R. Connell, S.L. Woo, R.D. Cheng, B.F. McArdle, C.W. Fuller, N.D. Halloran, and R.K. Wilson. 1992. DNA sequencing with dye-labeled terminators and T7 DNA polymerase: effect of dyes and dNTPs on incorporation of dye-terminators and probability analysis of termination fragments. Nucleic Acids Res. 20: $2471-2483$.

6. Voss, H., C. Schwager, U. Wirkner, J. Zimmermann, H. Erfle, N. Hewitt, T. Rupp, J. Stegemann, and W. Ansorge. 1992. New procedure for automated DNA sequencing with multiple internal labeling by fluorescent dUTP. Methods Mol. Cell. Biol. 3: 30-34.

7. Voss, H., S. Wiemann, U. Wirkner, C. Schwager, J. Zimmermann, J. Stegemann, H. Erfle, N.A. Hewitt, T. Rupp, and W. Ansorge. 1992. Automated DNA sequencing system resolving 1,000 bases with fluorescein-15-*dATP as internal label. Methods Mol. Cell. Biol. 3: 153-155.

8. Zimmermann, J., H. Voss, S. Wiemann, H. Erfle, T. Rupp, N.A. Hewitt, C. Schwager, J. Stegemann, and W. Ansorge. 1992. Cycle sequencing protocol with fluorescein-12-dCTP. Methods Mol. Cell. Biol. 4: $27-28$.

9. Sauda, K., T. Imasaka, and N. Ishibashi. 1986. Determination of protein in human serum by high-performance liquid chromatography with semiconductor laser fluorometric detection. Anal. Chem. 58: 2649-2653.

10. Patonay, G. and M.D. Antoine. 1991. Near-infrared fluorogenic labels: new approach to an old problem. Anal. Chem. 63: $321 \mathrm{~A}-327 \mathrm{~A}$

11. Strekowski, L., M. Lipowska, and G. Patonay. 1992. Facile derivatizations of heptamethine cyanine dyes. Synth. Commun. 22: 2593-2598.

12. Lipowska, M., G. Patonay, and L. Strekowski. 1993. New near-infrared cyanine dyes for labelling of proteins. Synth. Commun. 23: 3087-3094.

13. Narayanan, N. and G. Patonay. 1995. A new method for the synthesis of heptamethine cyanine dyes: Synthesis of new near-infrared fluorescent labels. $J$. Org. Chem. 60: 2391-2395.

14. Williams, R.J., M. Lipowska, G. Patonay, and L. Strekowski. 1993. Comparison of covalent and noncovalent labeling with 
near-infrared dyes for the high-performance liquid chromatographic determination of human serum albumin. Anal. Chem. 65: 601-605.

15. Middendorf, L.R., J.C. Bruce, R.C. Bruce, R.D. Eckles, D.L. Grone, S.C. Roemer, G.D. Sloniker, D.L. Steffens, S.L. Sutter, J.A. Brumbaugh, and G. Patonay. 1992. Continuous, on-line DNA sequencing using a versatile infrared laser scanner/electrophoresis apparatus. Electrophoresis 13: $487-494$.

16. Shealy, D.B., M. Lipowska, J. Lipowski, N. Narayanan, S. Sutter, L. Strekowski, and G. Patonay. 1995. Synthesis, chromatographic separation, and characterization of near-infrared-labeled DNA oligomers for use in DNA sequencing. Anal. Chem. 67: 247-251.

17. McIndoe, R.A., L. Hood, and R. Bumgarner. 1995. An analysis of the dynamic range and linearity of an infrared DNA sequencer. Electrophoresis (in press).

18. Middendorf, L.R., J.A. Brumbaugh, D.L. Grone, C.A. Morgan, and J.L. Ruth. 1988. Large scale DNA sequencing. Am. Biotechnol. Lab. 6: 14-22.

19. Steffens, D.L., S.L. Sutter, and S.C. Roemer. 1993. An alternate universal forward primer for improved automated sequencing of M13. BioTechniques 15: 580-582.

20. Chen, E.Y. and P.H. Seeburg. 1985. Supercoil sequencing: $A$ fast and simple method for sequencing plasmid DNA. DNA 4: 165-170.

21. Sambrook, J., E.F. Fritsch, and T. Maniatis. 1989. Molecular cloning: A laboratory manual, 2nd ed. p. C.5. Cold Spring Harbor Laboratory Press, Cold Spring Harbor, New York..

22. Tabor, S. and C.C. Richardson. 1987. DNA sequence analysis with a modified bacteriophage T7 DNA polymerase. Proc. Natl. Acad. Sci. 84: 4767-4771.

23. Wiemann, S., T. Rupp, J. Zimmermann, H. Voss, C. Schwager, and W. Ansorge. 1995. Primer design for automated DNA sequencing utilizing T7 DNA polymerase and internal labeling with fluorescein-15dATP. BioTechniques 18: 688-697.

24. Saiki, R.K., D.H. Gelfand, S. Stoffel, S.J. Scharf, R. Higuchi, G.T. Horn, K.B. Mullis, and H.A. Erlich. 1988. Primer-directed enzymatic amplification of DNA with a thermostable DNA polymerase. Science 239: 487-491.

25. Erlich, H.A., D. Gelfand, and J.J. Sninsky. 1991. Recent advances in the polymerase chain reaction. Science 252: 1643-1651.

26. Weber, J.L. and P.E. May. 1989. Abundant class of human DNA polymorphisms which can be typed using the polymerase chain reaction. Am. J. Hum. Genet. 44: 388-396.

27. Edwards, A., A. Civitello, H.A. Hammond, and C.T. Caskey. 1991. DNA typing and genetic mapping with trimeric and tetrameric tandem repeats. Am. $J$. Hum. Genet. 49: 746-756.

28. Schwengel, D.A., A.E. Jedlicka, E.J. Nanthakumar, J.L. Weber, and R.C. Levitt. 1994. Comparison of fluorescence-based semi-automated genotyping of multiple microsatellite loci with autoradiographic techniques. Genomics 22: 46-54.

29. Flejter, W.L., J.F. Kukowska-Latallo, S. Kiousis, S.C. Chandrasekharappa, S.E. King, and J.S. Chamberlain. 1993. Tetranucleotide repeat polymorphism at D17S846 maps within $40 \mathrm{~kb}$ of GAS at 17q12-q22. Hum. Wol. Genet. 2: 1080.

30. Miki, Y., J. Swensen, D. Shattuck-Eidens, P.A. Futreal, K. Harshman, S. Tavtigian, Q. Liu, C. Cochran, L.M. Bennett, W. Ding, R. Bell, J. Rosenthal, C. Hussey, T. Tran, M. McClure, C. Frye, T. Hattier, R. Phelps, A. Haugen-Strano, H. Katcher, K. Yakumo, Z. Gholami, D. Shaffer; S. Stone, S. Bayer, C. Wray, R. Bogden, P. Dayananth, J. Ward, P. Tonin, S. Narod, P.K. Bristow, F.H. Norris, L. Helvering, P. Morrison, P. Rosteck, M. Lai, J.C. Barrett, C. Lewis, S. Neuhausen, L. Cannon-Albright, D. Goldgar, R. Wiseman, A. Kamb, and M.H. Skolnick. 1994. A strong candidate for the breast and ovarian cancer susceptibility gene BRCA1. Science 266: $66-71$.

Received July 26, 1995; accepted in revised form October 18, 1995. 


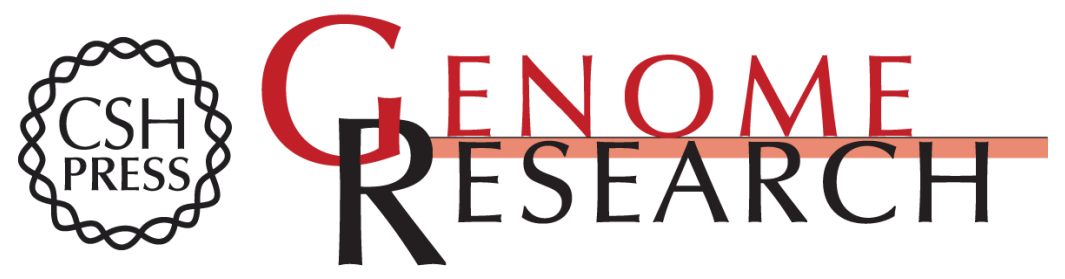

\section{An infrared fluorescent dATP for labeling DNA.}

D L Steffens, G Y Jang, S L Sutter, et al.

Genome Res. 1995 5: 393-399

Access the most recent version at doi:10.1101/gr.5.4.393

References This article cites 27 articles, 5 of which can be accessed free at:

http://genome.cshlp.org/content/5/4/393.full.html\#ref-list-1

\section{License}

Email Alerting Receive free email alerts when new articles cite this article - sign up in the box at the Service top right corner of the article or click here.

\section{Affordable, Accurate} Sequencing.

To subscribe to Genome Research go to:

https://genome.cshlp.org/subscriptions 